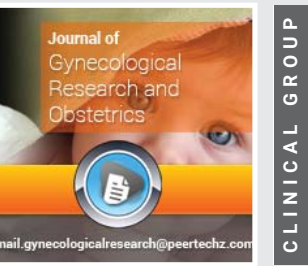

\section{The Use of Birth Plan to Support Waterbirth: A Qualitative Approach}

\author{
Joyce da Costa Silveira de Camargo ${ }^{1}$, Nádia Zanon \\ Narchi2*, Kelly Cristina Máxima Pereira Venâncio ${ }^{3}$, \\ Fernanda Marçal Ferreira ${ }^{3}$, Cindy Ferreira Lima ${ }^{3}$, Manuela \\ Néné $^{4}$ and Maria Catarina LR Grande ${ }^{5}$ \\ 1Professor, IBSAS, University of Porto, Portugal, and Midwifery Program of the School of Arts, \\ Sciences and Humanities of The University of São Paulo, São Paulo, Brazil \\ ${ }^{2}$ Professor, Midwifery Program of the School of Arts, Sciences and Humanities of the University of São \\ Paulo, São Paulo, Brazil \\ ${ }^{3}$ PhD Student, University of São Paulo, São Paulo, Brazil \\ ${ }^{4}$ Professor and Coordinator of School of Health of Portuguese Red Cross, (CINTESIS - NursID), Lisbon, \\ Portugal \\ ${ }^{5}$ Assistant Professor, Faculty of Psychology and Educational Sciences of the University of Porto, \\ Portugal
}

Received: 24 April, 2020

Accepted: 06 May, 2020

Published: 07 May, 2020

*Corresponding author: Nádia Zanon Narchi, Professor, Midwifery Program of the School of Arts, Sciences and Humanities of the University of São Paulo, São Paulo, Brazil, E-mail:nzn@usp.br

Keywords: Prenatal education; Waterbirth; Public health; Health policy; Midwifery

https://www.peertechz.com

\section{Check for updates}

\title{
Abstract
}

Background: The professional resistance to childbirth in water and the limitation of robust scientific evidence to support its safety constitute a context prone to the restriction of women's freedom of choice. The elaboration of the birth plan by pregnant women who wish to experience a birth immersed in water can be an important instrument for the exercise of their choice and autonomy. This qualitative and descriptive case study aim to realize how women experienced their birth plan in two hospitals in Portugal.

Results: Face-to-face and videoconferencing interviews were conducted with sixteen women witch speeches were recorded, transcribed, and submitted to content analysis, with the support of NVivo software. The mainly characteristics of the participants were: $76 \%$ had a higher level of schooling; $66 \%$ lived in a stable union with a partner; $66,7 \%$ were nulliparous; $100 \%$ were informed and prepared during prenatal sessions about waterbirth and made their birth plan with those sessions; $100 \%$ were at term gestation at the time of birth; $100 \%$ were referred for immersion in hot water during labour; after birth, all the newborns had Aqua Apgar index between 9 and 10 in the first minute and 10 in the fifth minute. The qualitative analysis allowed to identification of three thematic categories: Legitimising women's choices; Professional resistance and the devaluation of the birth plan: triggers of violence; and, Complete birth plan success.

Conclusion: The data showed that birth plan represented a legitimator of women's choices for experiencing waterbirth, although some of them perceived disregard and disrespect of the plan by health professionals, especially in a context of technocratic model of care. It was found that the birth plan represented a transcendence of the experience of labour and birth, enabling women to experience their choices with fullness, freedom, and specially respect.

\section{Introduction}

Immersion in water during labour and delivery has been increasingly offered in various obstetric care settings around the world. In addition to allowing greater autonomy and the experience of an active delivery for the woman, the increase in its use may be related to the analgesic action of the water and to the smaller number of interventions, which results in greater maternal satisfaction [1].

Studies worldwide show that waterbirth is safe and provides numerous benefits, including increased privacy, pain 
relief, freedom of movement, and reduction of unnecessary interventions, such as excessive numbers of vaginal touches and episiotomies $[2,3]$.

However, there are arguments against waterbirth that support the resistance of some professionals and relate to possible unfavourable neonatal outcomes, the risk of infection and postpartum haemorrhage, and the impossibility of continuous maternal-fetal monitoring and medical interventions $[1,4]$. It is worth noting that there is limited scientific knowledge of waterbirth considering the diversity of possible places for childbirth and models of care. Unfortunately, interest in supporting and financing research for natural methods of delivery are minimally equivalent to the investment in obstetric surgical interventions [5].

Giving women an informed choice in relation to delivery in water entails presenting them with both the benefits and costs (advantages and disadvantages) of this type of birth. An important instrument that can be used for this purpose is a birth plan created in conjunction with professionals, pregnants and families during prenatal assistance. It should be borne in mind that any plan for any institution and care model requires that the choice of the woman/family be flexible and open to change at any time depending on the unfolding progression of the woman's/child's experience of labour and birth, possibly eliminating childbirth in water as an option due to the unforeseen [6].

The birth plan is a powerful strategy to equalise interpersonal relationships in the scenario of childbirth since its creation ideally should involve both the woman and companion as well as the professionals working in perinatal care [7].

The birth plan describes, according to women's preferences, how labour and delivery will be managed under normal conditions [8]. It is, therefore, a document that seeks to legitimise and sustain choices so that women can give birth in a conscious, informed, and respectful way [9].

The cited professional resistance to waterbirth and the limitation of robust scientific evidence to support its safety restrict women's freedom of choice, which results in the low use of this modality of birth in several countries. From this perspective, the creation of the birth plan by pregnant women who wish to experience a waterbirth can be an important instrument in guaranteeing this choice in places where it exists and, consequently, to enable women to exercise their autonomy in that choice.

Therefore, the aim of this research is to realize how women experienced their birth plan in a hospital environment that uses waterbirth. This research assumes that women who choose to have a waterbirth can count on the birth plan as a legitimising instrument for their choices.

\section{Methods}

This is qualitative and descriptive research carried out in two hospitals of Portugal: one public, the first to implement a project of waterbirth in the country, and another private, in which independent midwives performed the birth in water. The choice of venues was purposeful, considering the availability of waterbirth assistance in the health services of the country.

We consider it is important to add that the birth plan has been legally established in the country as part of routine care for women during prenatal care, at which time women are encouraged to make the plan, taking into account the various care options in case of low risk or complications.

Sixteen women from four districts of Portugal (Setubal, Lisbon, Porto and Coimbra) participated in the study according to the following criteria: they experienced waterbirth in the study scenarios, did not use pharmacological methods for the relief of pain in labour and birth, and had a gestational age of 37 or more weeks. Those women whose births occurred out of the water were excluded from the study, even if there was immersion in the pool during labour.

The participants were recruited through the snowball sampling, where women were indicated by other participants for the interviews. Data collection was through structured interviews, from October 2015 to September 2016, with a script containing questions about the experience of the preparation of the birth plan which included water birth in the cited hospitals The interviews, which averaged 60 minutes in length, were conducted in person (face-to-face at home, work, café bars or squares) or by videoconference and recorded on a digital device. All the interviews were always conducted by a single interviewer, who is the first author of this research.

All the interviews were full transcribed for analysis and interpretation of its contents in order to guarantee the integrity and reliability of the information. It was adopted the technique of Content Analysis, following a design of systematic procedures for the analytical description of the information and meanings contained in the messages with inferences of knowledge regarding the conditions of production of the text $[10]$.

The analysis comprised three steps. In the pre-analysis, a floating reading of the transcribed interviews was carried out, with the constitution of the textual corpus. The material was treated and interpreted, identifying the organising nucleus of the content of the messages, which later formed categories, expressing consensus and particularities in the group studied [10].

The transcribed content of the interviews, in its entirety, was processed using the Nvivo ${ }^{\circledR}$ software version 10 , which supported the research for the coding of speeches and later grouping of the themes with the reports of women about their experiences with waterbirth.

As for the ethical aspects of this research, all women participated after voluntarily signing the Terms of Free and Informed Consent. The present study had ethical approval registered in Process $n^{0}$ 5145/2015 and was authorised by the National Commission of Data Protection in the Portugal (CNPD) under authorisation number 9885/2015. 


\section{Results}

The study participants were predominantly 35 to 45 years of age. Of these, $76 \%$ had a higher level of schooling, and $66 \%$ lived in a stable union with a partner. Regarding their reproductive characteristics, most of the women were nulliparous $(66.7 \%)$, with only one woman having a history of prenatal abortion.

All the women made their plan birth after being informed about the specific aspects of waterbirth in a prenatal information session, and they attended a course of preparation for waterbirth, which consisted of breathing classes, movement, and exercises in the water performed with their partners. Most of the births occurred in the public hospital (71.4\%), while the others took place in the private hospital $(28.6 \%)$.

At the time of birth, all participants were at term gestation, and $47.4 \%$ were at 40 weeks or more of gestational age. In $90 \%$ of the cases, the rupture of the pouch was spontaneous during labour, and the Aqua Apgar index, which is specific for the evaluation of newborns (NB) in water delivery, was between 9 and 10 in the first minute and 10 for all the NB in the fifth minute.

The analysis of the interviews allowed the identification of three thematic categories, which are presented below.

\section{Legitimising women's choices}

In this category the narratives indicate that the women of this study perceived the birth plan as an instrument with which to legitimise their preferences for labour and birth, in a context of hospital care that is sometimes resistant to waterbirth. Some of the women speeches are presented below:

I told the nurse - I want a waterbirth - and I put the birth plan on the table ... and told the $G$ [companion] to come in. He stayed with me (W1).

I told her, a little fear, the question that not all women get waterbirth the way they want, but I had a birth plan and wanted a waterbirth (W1).

I delivered my birth plan in which I was very explicit that I wanted to go into the water and refuse the epidural [...] and only have intermittent monitoring to be able to have all my freedom of movement $[\ldots](\mathrm{W} 3)$.

[...] the nurse's downstairs [delivery unit] called up and said [parenting unit]: she has a birth plan, so ask to see if she has any available room [...] (W6).

We did the initial care [...] and I said, 'Look, here is my birth plan; do not miss this because I want to have her in the water.' (W16).

[...] we are fighting as a women's-rights movement, but we need a lot of women, we need a voice, we need them to go to hospitals, to ask for what they want, to speak up for their preferences, to make their plans for childbirth [...] (W5).

Although all participants were eligible for waterbirth according to institutional criteria and had submitted a birth plan requesting it, some reported that the birth plan alone did not ensure the feasibility of their choices and was subject to professional approval of their health, like at:

[...] I presented my birth plan to ask for the waterbirth ... the doctor accepted the birth plan and gave permission [...] (W9).

He [the doctor] did not look me in the eye anymore; he did not sign my birth plan [...] (W5).

[...] I had already shown the plan to my obstetrician and everything was in order (W3).

Professional resistance and devaluation of the birth plan: triggers of violence

In this category we include statements of women who described resistant reactions from health professionals regarding their birth plan. Follow some speeches:

I was seen by a doctor; I presented my birth plan [...] but he was reluctant to release me for the waterbirth (W2).

This was something that worried me because I encounter some resistance when I presented my birth plan to the nurse; I had heard of the experiences of friends in A [another district] who took the plan but looked at the plan and just said - oh okay, okay! (W4).

I knew it was not a kind of consensual delivery (W5).

[...] but the way I was treated, in fact, the doctor did not hide that he was completely against childbirth in the water, but the first option - without knowing what I wanted - was to have an induction; he wanted to induce me immediately, but I not want this [...] (W5).

[...] there are a lot of people who make birthing plans and get them to the hospital and the nurses say - okay. The nurses from my experience and from what I have heard are sometimes more sensitive to these issues than the other health professionals (W10).

The women also realised that the birth plan gave rise to discouraging behaviour and professional discourse that could be characterised as institutional violence, like as follow:

The second [doctor] was like that - but you know [...] but look at [...] That thing from - 'ahhh the people come up with that idea but Okay, those are "very good" things to hear, sort of - let's see how it evolves' (W2).

When the contractions began to tighten, he [the doctor] told me, 'Why do you want to go through this? Why don't you take an epidural and walk?' And I said, 'Because I want to!' And he was seeing me with contractions and saying, 'I do not understand!' Then a nurse came to ask if I wanted something for the pain and I also told her that I did not but thanked her (W3).

[...] I did not even say that I wanted to have a natural childbirth and he saw it and said, 'Ah, so you are the one who wants to have a baby in the water and all that.' [...] he said that there were many women who died and I said that I was not going to die for sure [...] but then I was alone and I just thought that they [the professionals]

Citation: Silveira de Camargo JDC, Narchi NZ, Pereira Venâncio KCM, Ferreira FM, Lima CF, et al. (2020) The Use of Birth Plan to Support Waterbirth: A Qualitative Approach. J Gynecol Res Obstet 6(2): 024-030. DOI: https://dx.doi.org/10.17352/jgro.000081 
were going to boycott my birth plan, and I decided that I was going to run away from him [the doctor]. I did not see him any more during the whole shift (W5).

I told [the nurse], 'Look, I apologise but I do not want anything. I want to have a natural delivery.' Her response was very intimidating: 'Don't tell me you're one of those who want to have a waterbirth?' (W8).

Two women of this study had the perception that credibility and respect for the birth plan are related to issues such as public policies, health institutions and, especially, health professionals that present different attitudes and behaviours regarding to the planning of childbirth:

[...] with me I felt that the plan was important, at least that the team took it seriously(W4).

[...] I think that if I go today with a birth plan or with the birth plan that I took to deliver my son to S [a hospital], to another hospital, that it will be put aside - it will not be considered - because if even though I had not had it at waterbirth, I had other choices there, other options, but I'm not sure if that would be considered and respected. I think that on the one hand, it might have been necessary for the Portuguese State to create legislation that would guarantee or protect these conditions, but on the other hand, legislation does not contribute to the education of the professionals themselves (W9).

\section{Complete birth plan success}

Some of the women were surprised when they found a scenario different from that imagined and expected, which resulted in statements that determined this category in which positive experiences of women were thus portrayed:

From the beginning I felt welcomed, I felt supported, being in a hospital context. Right there, from the beginning I did not even remember that I was in the hospital [...] I felt respected. [...] we had total freedom. When I asked to go to the shower, I went, so I did not feel the hospital context (W1).

[...] the father cut the cord and it occurred after it [the cord] stopped pulse. They respected all this. I had written in the birth plan, but it was not accurate, they were very dear, they did not rush anything, it was everything in our time (W5).

\section{[...] they respected everything I wrote in my birth plan letter [...]} (W6).

I think there is a lot to do, I do not know where to start, but maybe the issue of respecting women in labour, respecting their wishes, because there is a lot that can be done without changing anything [...] (W10)

\section{Discussion}

The analysis of the qualitative results of the first category allows us to consider that the birth plan was an important instrument to legitimise women's preferences for waterbirth. As previously mentioned, this document has been developed to contribute to women's decision making about childbirth as well as the procedures to which their bodies may subjected, offering valuable details for caregivers about women's knowledge during prenatal care [11].

Thus, thinking about the birth plan as a tool to integrate women and health professionals based on dialogue can contribute to avoid disagreements and tensions during childbirth care especially in the hospital setting, sometimes resistant to women's choices and especially to waterbirth [11,12]. As highlighted, the birth plan was a factor that legitimized the choice of women, a result corroborated by another research in which women associated the plan with respect for freedom that gave them a leading role in birth scenario [12].

The informed consent and the respect of autonomy are important ethical principles of the care. Thus, women who made birth plans with high-quality information, based on scientific evidence, can make informed decisions during childbirth [11]. In this sense, a study showed that the act of creating a plan, in addition to be an educational process, also allow women to express their expectations and preferences to their companions and/or partners [13].

An explanation of the physiological evolution of the childbirth and postpartum process, together with the adoption of beneficial care practices is present in the creation of the birth plan, which enables the woman to both clarify doubts and fears and feel more supported [14]. The acceptance of the mentioned document by professionals responsible for following it guarantees respect for the autonomy that must be always respected in the care [15].

Originally, childbirth plans were created with the help of family and friends, when childbirth was an intimate event, experienced in the home [16]. It was fundamentally a planning of the labour, birth, and puerperium that addressed issues such as the woman's choice, the management of pain, the timing for calling the doctor or midwife, the logistics, the necessary supplies, and the environment so that birth would happen as desired [14].

Since the 1930s, when the birth event was institutionalised, the care model became technocratic, interventionist and sometimes violent [14]. Faced with this system of care, the birth plan has assumed a new role in the obstetric scenario, described for the first time in the 1980 s as an instrument to avoid unwanted and unnecessary interventions, to legitimize the desire and the participation of women in all decisions involving pregnancy, childbirth and puerperium [7].

This historical retrospective justifies the perception of the birth plan presented by the women of this study, especially when the choice was for waterbirth, a natural way of birth, in which medical interventions are minimal. The perception of these women about the birth plan reinforces the character that it acquired almost 40 years ago: a formal document that inhibits excessive interventions and protects the rights of women.

Thus, the birth plan becomes the axis of the clinical relationship established between the woman and the health 
professionals and guides the care during the whole process of labour and birth, which should be based on respect, companionship, and effective communication to promote a good labour-and-birth experience [17-19]. Problems with communication and an atmosphere of distrust are dilemmas that weaken decision making [18]. The search for a jointauthored birth plan, and for flexibility in its implementation, based on dialogue and respect, allow the creation of a more welcoming environment, and gives the woman greater confidence in the team [20].

Flexibility in planning is an important characteristic for both women and caregivers 21. However, this malleability should not be a pretext to disqualify women in their autonomy since this disregarding constitutes one of the pillars of the genesis of institutional violence [11,22]

The findings of the second category of this study show the fragility of these relationships when the woman's delivery plan was submitted for the approval in an unshared decisionmaking process. There is a professional resistance to delivery in water, sometimes expressed with intimidation and questioning about the choices presented in the birth plan, which in turn are indicators of professional resistance and/or violence.

The breakdown of effective and horizontal communication can occur when women meet professionals in childbirth care who did not participate in the process of building the birth plan throughout the prenatal period [11]. This is one of the causes of the perception of women in this research, who reported bad experiences with some health professionals. This is often a situation observed in different contexts around the world, in which obstetric care is fragmented, that is, during prenatal, childbirth and postpartum women are assisted by different caregivers with different views and knowledge about the childbirth and, especially, waterbirth.

In this sense, it's important to highlight that many women experience abuse, disrespect, mistreatment and neglect during childbirth in many health institutions all over the world. Such treatment not only violates women's rights to respectful care, but it also threatens the right to life, health, physical integrity, and non-discrimination [23].

Still in this context, sometimes troubled, of the negotiation of the birth plan between women and health professionals, there are those caregivers who justify their position because they believe that women arrive in health services with plans constructed in an uniformed and incompatible way with the reality of the obstetric care [11]

The women in this study sought waterbirth because it is a natural method of delivery, with a minimum of interventions, and they used the birth plan to guarantee this choice in a predominantly technocratic and confrontational context which reflects the core values of a society governed by a paradigm guided by science and technology. In this model, childbirth is understood as a dangerous and risky moment, requiring professional intervention. In that scope, when entering the hospital, the woman is already part of an "induced labour statistic", being the subject of a series of interventions: synthetic oxytocin, vaginal examinations, rupture of membranes, and at the time of delivery, the lithotomy position and episiotomy, as well as requiring force to push the baby into position going against what is physiological $[24,25]$.

Thus, it is not uncommon to observe resistance to the acceptance of the birth plan as reported by women. The presentation of this document to professionals does not necessarily guarantee that it will be respected, which can generate frustration and feelings of destitution of autonomy where women's bodies are concerned, sensation often related to the lack of dialogue $[15,26]$, as previously discussed.

Building dialogue and sharing decisions was important for the satisfaction of women during childbirth, even when the birth plan was not completely fulfilled [12]. To be oriented about decisions, feel herself respected throughout the process and trust the team are important success factors in obstetric care for women.

There are differing opinions among health professionals about the birth plan. While some see it as an important health education tool for women and families, others feel pressured when they are in front of the document. Some caregivers believe that the birth plan creates the expectation that childbirth can be controlled according to the choices expressed by the woman in it, when the parturition process can be oftentimes unpredictable [26].

The health professional's view of adopting the birth plan directly influences the woman's perception of respect for her rights and choices. Accordingly, dialogue and active participation provide satisfaction for women, even if the plan has not been fully met $[12,26,27]$.

On the other hand, when women are equipped with information and in search of protagonism in childbirth, they may feel constrained in the decision-making process when it's centred on the professional [17]. The perception of being autonomous in the choices, but dependent on care is something peculiar. In this sense, to avoid that some women are considered difficult to deal with, it is important to respect their autonomy and rights [27].

According to the women's perception in the third category, the birth plan gave them a pleasurable experience regarding the waterbirth process, resulting in satisfaction, respect, and acceptance-attributes that allowed them to forget that they were in a hospital environment, which transcends the cognitive comprehension capacity, but which is wonderful and converged in a positive experience of giving birth. Some of them were surprised when found a scenario different from that imagined and expected, which resulted in statements that determined this category in which positive experiences of women were thus portrayed.

A systematic review of the effect of the birth plan on the experience of giving birth refers to not having enough evidence to support or refute it as a tool capable of improving women's 
satisfaction [28]. However, the present study, as well as other surveys $[29,30]$, which evaluated the experiences of women who had their birth planning respected, demonstrated better satisfaction and success in the implementation of the plan, a simple technology that can contribute to the improvement of the obstetric care, which is frequently based on heavy technologies and on the biomedical model of care $[12,25]$.

In this research all women interviewed expressed a feeling of contentment related to the implementation of their birth plans in a unique context, that of waterbirth. Woman in birth yearn for a model of care centered on her and in her desires voices and expectations that are transmitted through the birth plan carefully thought out during pregnancy $[27,28,30]$.

Finally, it's important to note that a limitation of this study concerns the fact that it was developed in a hospital context in which both water delivery and the use of a birth plan are recent initiatives, for which women had yet limited access. Despite that, the results may support new research on the implementation of the birth plan and the water birth in health services in order to promote better assistance to women, families and newborns.

\section{Conclusion}

The findings of this research highlighted that women perceived and considered the birth plan to be an important legitimiser of their choices for waterbirth, although some nevertheless perceived disregard and disrespect of the document by health professionals in a context of authoritative care. However, the presentation of this personal instrument at the time of hospital admission for delivery did not guarantee that all the women's choices were respected or even approved, which characterizes one of the forms of institutional violence.

Despite the need for many controlled and randomized studies on the birth plan, and on the waterbirth, it is considered that this simple technology of care represented for the women of this study a transcendence of the experience of labour and birth, enabling them to experience their choices with fullness, freedom, and specially respect.

\section{References}

1. Cluett ER, Burns E, Cuthbert A (2018) Immersion in water during labour and birth. Cochrane Database Syst Rev. Link: https://bit.ly/3c9QZyk

2. Bovbjerg ML, Cheyney M, Everson C (2016) Maternal and newborn outcomes following waterbirth: The Midwives Alliance of North America Statistics Project, 2004 to 2009 Cohort. J Midwifery Womens Health 61: 11-20. Link: https://bit.ly/2SJnFai

3. Clews C, Church S, Ekberg M (2019) Women and waterbirth: A systematic meta-synthesis of qualitative studies. Women Birth (in press). Link: https://bit.ly/2L5QnxG

4. ACOG (2016) Immersion in water during labor and delivery. Number 679 Obstet Gynecol 123: 912. Link: https://bit.ly/2SJo0d4

5. Cole A, O'Neill P, Sampson C, Lorgelly P (2018) Barriers to Uptake of Minimal Access Surgery in the United Kingdom. OHE. Link: https://bit.ly/3ft7TtY

6. Narchi NZ, Venâncio KCMP, Ferreira FM, Vieira JR (2019) Individual birth planning as a teaching-learning strategy for good practices in obstetric care Rev Esc Enferm USP 53: e03518. Link: https://bit.ly/3ddrfBg

7. Kitzinger S (1992) Sheila Kitzinger's letter from England: birth plans. Birth 19: 36-37. Link: https://bit.ly/2zb3c7g

8. Afshar Y, Wang ET, Mei J, Esakoff TF, Pisarska MD, et al. (2017) Childbirth education class and birth plans are associated with a vaginal delivery. Birth 44: 29-34. Link: https://bit.ly/3frC6t0

9. Yam EA, Grossman AA, Goldman LA, García SG (2007) Introducing birth plans in Mexico: An exploratory study in a hospital serving low-income Mexicans. Birth 34: 42-48. Link: https://bit.ly/2zhqsQR

10. Bardin L (2016) Content Analysis (Análise de Conteúdo). São Paulo: Edições (In Portuguese)

11. DeBaets AM (2017) From birth plan to birth partnership: enhancing communication in childbirth. Am J Obstet Gynecol 216: 31.e1-31.e4. Link: https://bit.ly/3dmZnL6

12. Loiola AMR, AlvesVH, Vieira BDG, Rodrigues DP, Souza KV, et al. (2020) Delivery plan as a care technology: experience of women in the postpartum period in a birth center. Cogitare Enfermagem 25: 205-214. Link: https://bit.ly/2zevWfy

13. Aragon M, Chhoa E, Dayan R, Kluftinger A, Lohn Z, et al. (2013) Perspectives of expectant women and health care providers on birth plans. J Obstet Gynaecol Can 35: 979-985. Link: https://bit.ly/3baqIP3

14. Lothian J (2006) Birth plans: the good, the bad, and the future. J Obstet Gynecol Neonatal Nurs 35: 295-303. Link: https://bit.ly/2zhqW9D

15. Silva ALNV, Neves ABN, Sgarbi AKG, Souza RA (2017) Birth plan: a tool for women empowerment during the nursing care. Revista de Enfermagem da UFSM 7: 144-151. Link: https://doi.org/10.5902/217976922253

16. Nagahama EEI, Santiago SM (2005) The medical institutionalization of childbirth in Brazil. Ciência and Saúde Coletiva 10: 144-151. Link: https://bit.ly/2WanTcG

17. Fernández IDM, Sellés EM (2010) The birth plan. What do we know about it?. Matronas Profesión 11: 53-57. Link: https://bit.ly/3beVu9G

18. Suárez-Cortés $M$, Armero-Barranco D, Canteras-Jordana $M$, MartínezRoche MA (2015) Use and influence of delivery and birth plans in the humanizing delivery process. Rev Latino-am Enfermagem 23: 520-526. Link: https://bit.ly/2WtUMQw

19. WHO (2018) WHO recommendations: intrapartum care for a positive childbirth experience. Link: https://bit.ly/3fncnCg

20. Perry C, Quinn L, Nelson JL (2002) Case study: Birth plans and professiona autonomy. The Hastings Center Report 32: 12-13. Link: https://bit.ly/2yAkAT

21. Mei JY, Afshar Y, Gregory KD, Kilpatrick SJ, Esakoff TF (2016) Birth plans: what matters for birth experience satisfaction. Birth 43: 144-150. Link: https://bit.ly/2L3Ixov

22. Pereira WR (2004) Power, violence and symbolic domination in public health services. Texto and Contexto-Enfermagem 13: 391-400. Link: https://bit.ly/2A4d4QK

23. WHO (2014) Prevention and elimination of abuse, disrespect and mistreatment during childbirth in health institutions. Link: https://bit.ly/3c8mAk1

24. Diniz SG, Salgado HO, Andrezzo HFA, Carvalho PGC, Carvalho PCA, et al. (2015) Abuse and disrespect in childbirth care as a public health issue in Brazil: origins, definitions, impacts on maternal health, and proposals for its prevention. Rev Bras Crescimento Desenvolv Hum 25: 377-384. Link: https://bit.ly/2SFrtsO

Citation: Silveira de Camargo JDC, Narchi NZ, Pereira Venâncio KCM, Ferreira FM, Lima CF, et al. (2020) The Use of Birth Plan to Support Waterbirth: A Qualitative Approach. J Gynecol Res Obstet 6(2): 024-030. DOI: https://dx.doi.org/10.17352/jgro.000081 
25. Davis-Floyd R (2001) The technocratic, humanistic, and holistic paradigms of childbirth. Int J Gynaecol Obstet 75: S5-S23. Link: https://bit.ly/2SHSIDd

26. Medeiros RMK, Figueiredo G, Correa ÁCP, Barbieri M (2019) Repercussions of using the birth plan in the parturition process. Revista Gaúcha de Enfermagem 40: e20180233-e20180233. Link: https://bit.ly/3cdzMUE

27. Westergren A, Edin K, Walsh D, Christianson M (2019) Autonomous and dependent-the dichotomy of birth: a feminist analysis of birth plans in Sweden. Midwifery 68: 56-64. Link: https://bit.ly/2YBKKzm

28. Mirghafourvand M, Charandabi SMA, Ghanbari-Homayi S, Jahangiry L, Nahaee
J, et al. (2019) Effect of birth plans on childbirth experience: A systematic review. Int J Nurs Pract 25: e12722. Link: https://bit.ly/2ziFXrK

29. Kuo SC, Lin KC, Hsu CH, Yang CC, Chang MY, et al. (2010) Evaluation of the effects of a birth plan on Taiwanese women's childbirth experiences, control and expectations fulfilment: A randomised controlled trial. Int J Nurs Stud 47: 806-814. Link: https://bit.ly/2SFzpui

30. Farahat AH, Mohamed HES, Elkader SA, El-Nemer A (2015) Effect of Implementing a Birth Plan on Womens' Childbirth Experiences and Materna \& Neonatal Outcomes. Journal of Education and Practice 6: 24-31. Link: https://bit.ly/2L1CIYw

\section{Discover a bigger Impact and Visibility of your article publication with}

\section{Peertechz Publications}

\section{Highlights}

* Signatory publisher of ORCID

* Signatory Publisher of DORA (San Francisco Declaration on Research Assessment)

- Articles archived in worlds' renowned service providers such as Portico, CNKI, AGRIS, TDNet, Base (Bielefeld University Library), CrossRef, Scilit, J-Gate etc.

* Journals indexed in ICMJE, SHERPA/ROMEO, Google Scholar etc.

* OAI-PMH (Open Archives Initiative Protocol for Metadata Harvesting)

* Dedicated Editorial Board for every journal

* Accurate and rapid peer-review process

* Increased citations of published articles through promotions

* Reduced timeline for article publication

Submit your articles and experience a new surge in publication services (https://www.peertechz.com/submission).

Peertechz journals wishes everlasting success in your every endeavours.

Copyright: (c) 2020 Silveira de Camargo JDC, et al. This is an open-access article distributed under the terms of the Creative Commons Attribution License, which permits unrestricted use, distribution, and reproduction in any medium, provided the original author and source are credited. 